\title{
Aurelian Craiutu, Le Centre introuvable, la pensée politique des doctrinaires sous la Restauration
}

\section{Laurence Richer}

\section{(2) OpenEdition}

1 Journals

\section{Édition électronique}

URL : http://journals.openedition.org/studifrancesi/8952

DOI : 10.4000/studifrancesi.8952

ISSN : 2427-5856

Éditeur

Rosenberg \& Sellier

\section{Édition imprimée}

Date de publication : 1 octobre 2008

Pagination : 467

ISSN : 0039-2944

\section{Référence électronique}

Laurence Richer, «Aurelian Craiutu, Le Centre introuvable, la pensée politique des doctrinaires sous la Restauration », Studi Francesi [En ligne], 155 (LII | II) | 2008, mis en ligne le 30 novembre 2015, consulté le 09 janvier 2021. URL : http://journals.openedition.org/studifrancesi/8952 ; DOI : https://doi.org/ 10.4000/studifrancesi.8952

Ce document a été généré automatiquement le 9 janvier 2021.

\section{(c) $($ ) $\odot$}

Studi Francesi è distribuita con Licenza Creative Commons Attribuzione - Non commerciale - Non opere derivate 4.0 Internazionale. 


\title{
Aurelian Craiutu, Le Centre introuvable, la pensée politique des doctrinaires sous la Restauration
}

\author{
Laurence Richer
}

\section{RÉFÉRENCE}

AURELIAN CRAIUTU, Le Centre introuvable, la pensée politique des doctrinaires sous la

Restauration, traduit de l'anglais par Isabelle Hausser, Paris, Plon, 2007, pp. 368.

1 L'original du livre Liberalism under Siege: The Political Thought of the French Doctrinaires, a été publié en 2003 par Lexington Books aux États-Unis. Toutefois la traduction française a été l'occasion pour l'auteur d'apporter un certain nombre de modifications.

2 Dès l'avant-propos, on est invité à revisiter le mot «libéral». Touché par l'évolution historique du lexique politique, il est, plus que les autres, source d'incompréhension et de contresens. L'auteur part de l'idée que la réflexion française sur le libéralisme est mal connue des penseurs américains et se veut donc un lien entre les deux. Il affirme vouloir élargir la vision anglo-saxonne du libéralisme, née de Hobbes et de Locke, associée à l'utilitarisme. «On a tendance à confondre l'essence du libéralisme avec le libéralisme politique anglo-américain» (p. 277). Le lecteur européen ressent néanmoins l'impression d'une lecture téléologique, aboutissant au modèle de la démocratie aux États-Unis. Cela ne retire rien à l'intérêt du livre, grâce à la dimension internationale de la bibliographie, qui couvre plusieurs langues, et permet donc de n'omettre aucune des grandes figures du libéralisme, par exemple Pellegrino Rossi, mieux servi par la critique italienne que française.

3 L'auteur affirme la place des doctrinaires dans la pensée libérale. Il recherche longuement l'influence qu'ils ont eue sur Tocqueville dans des domaines capitaux comme la définition de la démocratie. Un clair rappel des circonstances historiques est fait, et la réhabilitation de Guizot poursuivie. Le lectorat littéraire retiendra 
l'intéressante exposition de sa politique en matière d' "instruction publique», ce qui inclut l'action culturelle. Cette approche compense des analyses un peu courtes sur le rapport entre le politique d'une part, les arts et les lettres d'autre part. C'est aussi à partir de la pensée de Guizot qu'est proposée une définition fine d'un libéralisme qui se concilie avec «sa croyance dans le rôle positif que le pouvoir exécutif pouvait et devait jouer dans la société moderne» (p.159). On notera aussi ce qui est dit du rôle d'une raison qui, chez lui, «doit donc être comprise comme une stratégie libérale destinée à diviser et à limiter la souveraineté» (p. 137).

Les passages consacrés au gouvernement représentatif sont particulièrement évocateurs. L'auteur y met en valeur un beau texte de Guizot où il rappelle à ses contemporains que ce n'est pas seulement un «régime orageux et bruyant» mais aussi un régime tempéré par «la liberté de la tribune et la liberté de la presse» (pp. 211 et 325). On est là non seulement dans les idées politiques, mais aussi dans l'interrogation d'un siècle sur son système d'expression et de communication, qui inclut la littérature. On pense aux passages où des auteurs aussi différents que Chateaubriand ou Quinet évoquent les assemblées parlementaires. Ni l'un ni l'autre ne croient certes y voir une élite d'hommes éclairés, comme le souhaitent Guizot et Royer-Collard. Cela suppose donc que l'expression d'une opinion publique passe aussi par d'autres canaux. Le livre s'en tient sur ce sujet à des approches classiques mais convaincantes. La question de la liberté de la presse, essentielle dans l'histoire de notre XIX ${ }^{e}$ siècle, est traitée de façon cohérente, dans la perspective d'une transparence qui doit permettre d'étaler tous les actes du gouvernement sur la place publique: «l'aspect le plus original de Guizot était sa définition de la publicité comme pierre angulaire du gouvernement représentatif» (p. 239).

5 L'auteur conclut qu'après «l'hubris prométhéenne» de certains régimes, un libéralisme bien compris devrait porter à apprécier la valeur de modération en politique. Si actuelle qu'elle se veuille, sa conclusion évoquera pour le lecteur les sarcasmes et les déceptions de nos auteurs $\mathrm{du} \mathrm{xIX}^{\mathrm{e}}$ siècle, coincés entre l'attirance suspecte pour Napoléon et ces hommes sans prestige que ridiculisent leurs appellations mêmes de «juste-milieu» ou «doctrinaires». 